\title{
PRODUÇÃO DE MUDAS DE Schinopsis brasiliensis Engler SOB PRÉVIA LAVAGEM DO PÓ DE COCO E SUBMETIDAS A DOSES CRESCENTES DE FERTILIZANTE DE LIBERAÇÃO CONTROLADA
}

\section{PRODUCTION OF Schinopsis brasiliensis Engler SEEDLINGS UNDER WASHED COCONUT COIR FIBER AND INCREASING DOSES OF CONTROLLED RELEASE FERTILIZERS}

\author{
Leonardo Pereira da Silva Brito ${ }^{1}$ Thatiany Teixeira Bezerra ${ }^{2}$ Elaine Maiara Bonfim Nunes ${ }^{3}$ Márkilla \\ Zunete Beckmann Cavalcante ${ }^{4}$ José Alves de Siqueira Filho $^{5}$
}

\begin{abstract}
RESUMO
O manejo do substrato e da adubação é imprescindível para garantir a formação de mudas de espécies florestais com qualidade e que tenham êxito no estabelecimento em campo, seja para fins de arborização urbana, recuperação de áreas degradadas, projetos de reflorestamento ou para fins madeireiros. Nesse sentido, objetivou-se avaliar o efeito da lavagem do pó de coco e a aplicação de doses crescentes de fertilizante de liberação controlada na produção de mudas de baraúna (Schinopsis brasiliensis Engler). O experimento foi conduzido no período de 30 de janeiro de 2015 a 04 de abril de 2015, em viveiro (50\% de sombreamento) no Setor de Produção de Mudas do Centro de Referência para Recuperação de Áreas Degradadas da Caatinga ( $C R A D)$, Petrolina-PE. O delineamento experimental adotado foi inteiramente casualizado, com os tratamentos distribuídos em esquema fatorial $5 \times 2$, referentes a cinco doses do adubo Osmocote $^{\circledR}\left(0,0 ; 4,5 ; 9,0 ; 13,5\right.$ e $\left.18,0 \mathrm{~kg} \mathrm{~m}^{-3}\right)$ e substrato lavado ou não lavado, com quatro repetições e 54 tubetes por parcela. Durante o experimento foram registrados a porcentagem de emergência (PE\%) e o índice de velocidade de emergência (IVE). Ao final do experimento, foram determinados: altura de planta; número de folhas; diâmetro do caule; comprimento médio da maior raiz; área foliar; clorofila foliar; e massa seca da parte aérea e raiz. A alta salinidade no substrato pó de coco compromete o desenvolvimento inicial de mudas de baraúna, indicando-se a necessidade da lavagem do substrato para se realizar a produção de mudas. A lavagem do pó de coco em associação com fertilizante de liberação controlada proporciona mudas de melhor qualidade. As doses de adubo de liberação controlada influenciam positivamente o crescimento inicial das mudas de baraúna, incrementando todas as variáveis em estudo. O fertilizante de liberação controlada pode ser recomendado para a formação de mudas de baraúna, na dose de até $12,75 \mathrm{~kg} \mathrm{~m}^{-3}$.
\end{abstract}

Palavras-chave: Baraúna; salinidade; Osmocote ${ }^{\circledR}$; nutrição de plantas.

\begin{abstract}
The management of the substrate and fertilization is essential to ensure the formation of forest species seedlings with quality and succeed in establishing in the field, either for the purpose of urban forestry, recuperation of degraded areas, reforestation projects or wood purposes. In this sense, the objective was to evaluate the effect of washed coconut coir fiber and increasing doses of controlled release fertilizer in producing seedlings of baraúna (Schinopsis brasiliensis Engler). The experiment was carried out from

1 Engenheiro Agrônomo, MSc., Doutorando em Agronomia, Universidade Federal de Lavras, Campus Universitário, Av. Doutor Sylvio Menicucci, 100, Caixa Postal 3037, CEP 37200-000, Lavras (MG), Brasil. leonardobrito@ufpi. edu.br

2 Bióloga, Mestranda em Botânica, Universidade Federal Rural de Pernambuco, Rua Manoel de Medeiros, s/n, CEP 52171-900, Recife (PE), Brasil. thatiany.tb@hotmail.com

3 Bióloga, Rod. BR 407, KM 12, s/n, CEP 56300-990, Petrolina (PE), Brasil. ebonfimnunes@gmail.com

4 Engenheira Agrônoma, $\mathrm{Dr}^{\mathrm{a}}$., Professora Associada da Universidade Federal do Vale do São Francisco, Rod. BR 407, km 12, s/n, CEP 56300-990, Petrolina (PE), Brasil. markilla.beckmann@univasf.edu.br

5 Biólogo, Dr., Professor Associado da Universidade Federal do Vale do São Francisco, Rod. BR 407, km 12, s/n, CEP 56300-990, Petrolina (PE), Brasil. jose.siqueira@univasf.edu.br
\end{abstract}

Recebido para publicação em 13/09/2016 e aceito em 7/07/2017

Ci. Fl., v. 28, n. 3, jul. - set., 2018 
January 30, 2015 to April 4, 2015, in the nursery (50\% shade) in the areas of Seedling Production at Reference Center for Recovery Degraded Areas of Caatinga (CRAD) at the Federal University of the São Francisco Valley (UNIVASF), Petrolina-PE. The experimental design was completely randomized, with treatments distributed in a $5 \times 2$ factorial arrangement for five doses of fertilizer Osmocote ${ }^{\circledR}(0.0 ; 4.5 ; 9.0$;

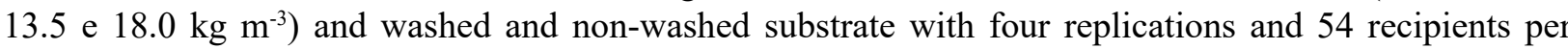
plot. During the experiment were recorded emergency percentage (\% PE) and the emergence speed index (IVE). At the end of the experiment were determined theplant height; number of leaves; stem diameter; average length of roots; leaf area; leaf chlorophyll; and dry weight of shoot and root. The high salinity in the substrate coconut fiber compromises the initial development of baraúna seedlings, indicating the need of washing the substrate to produce seedlings. Washing coconut powder in association with the use of controlled release fertilizer promotes better quality seedlings. The doses of controlled release fertilizer positively influence the initial growth of baraúna seedlings, increasing all studied variables. The controlled release fertilizer can be recommended for the formation of baraúna seedlings at a dose of up to $12.75 \mathrm{~kg} \mathrm{~m}^{-3}$. Keywords: Baraúna; salinity; controlled-release fertilizer; plant nutrition.

\section{INTRODUÇÃO}

O semiárido brasileiro abrange uma área correspondente a 74,30\% da Região Nordeste e $11 \%$ da superfície do Brasil (PAES; MORAIS; LIMA, 2004). A vegetação do semiárido, predominantemente a Caatinga, é composta de uma variedade de espécies arbóreas e arbustivas, e embora apresente alta diversidade biológica, vem suportando contínua devastação, perdendo-se com isto várias espécies características da região (GONZAGA et al., 2003; XAVIER et al., 2011). De acordo com a lista oficial das espécies da flora brasileira, 47 espécies do Bioma Caatinga estão ameaçadas de extinção, dentre as quais, encontra-se a baraúna (Schinopsis brasiliensis Engler), pertencente à família Anacardiaceae (BRASIL, 2008b). É considerada uma das árvores nobres da Caatinga, pois fornece madeira de boa qualidade, mas a exploração excessiva e sem reposição levou ao quase esgotamento das reservas dessa espécie (MAIA, 2004; MARTINELLI; MORAES, 2013), sendo hoje protegida de modo integral, incluindo a proibição de coleta, corte, transporte, armazenamento, manejo, beneficiamento e comercialização (BRASIL, 2014). Além da utilidade madeireira, também é considerada uma árvore ornamental, podendo ser utilizada na arborização de praças e jardins (SIQUEIRA FILHO et al., 2009).

O plantio de espécies florestais nativas é uma alternativa de manejo na redução dos impactos das atividades humanas (NUNES; SOUZA, 2011). Considerando que a baraúna se apresenta como uma das espécies da Caatinga cuja população está reduzida e por apresentar notável potencial econômico e ambiental, há necessidade da adoção de programas de incentivo à conservação e multiplicação desta espécie. No entanto, há carência de informações sobre esta espécie, principalmente de estudos voltados para o estabelecimento de protocolos de produção de mudas, que possam servir de apoio para empreendimentos neste setor. Mudas de qualidade são essenciais para assegurar o sucesso das ações de revegetação, resgate de germoplasma e estabelecimento de povoamentos, quer seja com fins comerciais ou conservacionistas (CRUZ; ANDRADE; FEITOSA, 2016). Assim, esta produção, se de boa qualidade, possibilita maior potencial de sobrevivência e crescimento após o plantio, muitas vezes dispensando o replantio e reduzindo a demanda por tratos culturais de manutenção. Uma muda de boa qualidade deve-se apresentar vigorosa, com folhas de tamanho e coloração típicas da espécie e ainda em bom estado nutricional.

Dentre os insumos para produção de mudas, é preciso atentar-se ao substrato, no qual além do custo e disponibilidade garantir que as propriedades químicas e físicas do mesmo atendam, ao máximo, às condições para o bom crescimento adequado das plantas (CALDEIRA et al., 2012). O uso de materiais renováveis na formulação de substratos é de fundamental importância, haja vista a questão ambiental, bem como, o aumento da produção de mudas, que deve seguir os padrões de sustentabilidade (KRATZ; WENDLING; SOUZA, 2013). Faz-se necessário o fornecimento de novos insumos a serem utilizados como substratos, em busca de apresentar novas possibilidades de formulação desse produto, como o uso de resíduos agroindustriais, industriais florestais e urbanos para a produção de mudas, representando uma alternativa viável, pois grandes volumes destes produtos são gerados, representando um problema ambiental se não for apresentado um destino final adequado. 
Conforme Oliveira, Hernandez e Assis Júnior (2009), o pó de coco é um excelente material orgânico para formulações de substratos devido às suas propriedades de retenção de água, aeração do meio de cultivo e estimulador do enraizamento, mostrando a possibilidade da utilização deste resíduo como substrato agrícola. No entanto, a alta salinidade presente no pó de coco pode acarretar em alta condutividade elétrica. Segundo Matias et al. (1999), a fibra de coco não lavada além de retardar a germinação proporciona um crescimento menor das mudas, porém, de acordo com Oliveira et al. (2011), a tolerância à salinidade é variável entre espécies e, mesmo dentro da espécie, entre estádios de desenvolvimento. Para Bosco et al. (2009), a salinidade também interfere na composição mineral das folhas com interferência nos processos fisiológicos.

Aliado a um bom substrato e seu manejo, deve ser utilizado um adubo de qualidade e em doses adequadas. De acordo com Rossa et al. (2015), o Osmocote ${ }^{\circledR}$, adubo de liberação controlada de nutrientes, vem sendo utilizado com certa frequência na produção de mudas em recipientes. Mendonça et al. (2008) relatam que o Osmocote ${ }^{\circledR}$ disponibiliza de forma contínua os nutrientes para as mudas, durante um maior tempo, o que permite uma menor possibilidade de ocorrer deficiência de nutrientes durante o período de formação das mudas, dispensando aplicações parceladas de outras fontes, e com isso, reduzindo os custos operacionais na formação da muda. Diante do exposto, objetivou-se avaliar o efeito da lavagem do pó de coco e o uso de doses crescentes de fertilizante de liberação controlada na produção de mudas de Schinopsis brasiliensis Engler.

\section{MATERIAL E MÉTODOS}

Frutos maduros de Schinopsis brasiliensis Engler foram coletados em novembro de 2014 (período de frutificação), diretamente de 10 árvores-matrizes (cerca de $12 \mathrm{~m}$ de altura) em uma população natural, localizada no povoado Caboclo, que faz parte da ecorregião Depressão Sertaneja Meridional, pertencente ao município de Afrânio-PE, nas coordenadas geográficas $08^{\circ} 28^{\prime} 06,90^{\prime \prime} \mathrm{S}, 40^{\circ} 56^{\prime} 06^{\prime}$ "W e altitude média de 588 metros. O clima da região, na classificação climática de Köppen, é do tipo BSh com temperatura média de $24,7^{\circ} \mathrm{C}$ e pluviosidade média anual $556 \mathrm{~mm}$. Após a coleta, os frutos foram postos para secar ao ar livre durante dois dias e beneficiados manualmente. As sementes foram armazenadas por cerca de dois meses até o início do experimento.

O experimento foi conduzido no período de 30 de janeiro de 2015 a 04 de abril de 2015, em viveiro (50\% de sombreamento) no Setor de Produção de Mudas do Centro de Referência para Recuperação de Áreas Degradadas da Caatinga (CRAD) na Universidade Federal do Vale do São Francisco (UNIVASF), Petrolina-PE, nas coordenadas geográficas $09^{\circ} 19^{\prime} 28^{\prime}$ 'S, 40³3'34"W e altitude média de 376 metros. Segundo a classificação climática de Köppen, o clima da região é do tipo Bswh - semiárido (quente e seco), com a ocorrência de duas estações bem diferenciadas: estação seca entre os meses de maio e outubro e a estação chuvosa entre os meses de novembro e abril, com precipitação pluviométrica média de $431,8 \mathrm{~mm} /$ ano. Durante a condução do experimento, foram obtidos os dados de temperatura média do ar, umidade relativa do ar e pluviosidade, registrados na Estação Meteorológica Automática da UNIVASF, situada em torno de 500m do viveiro (Figura 1). 


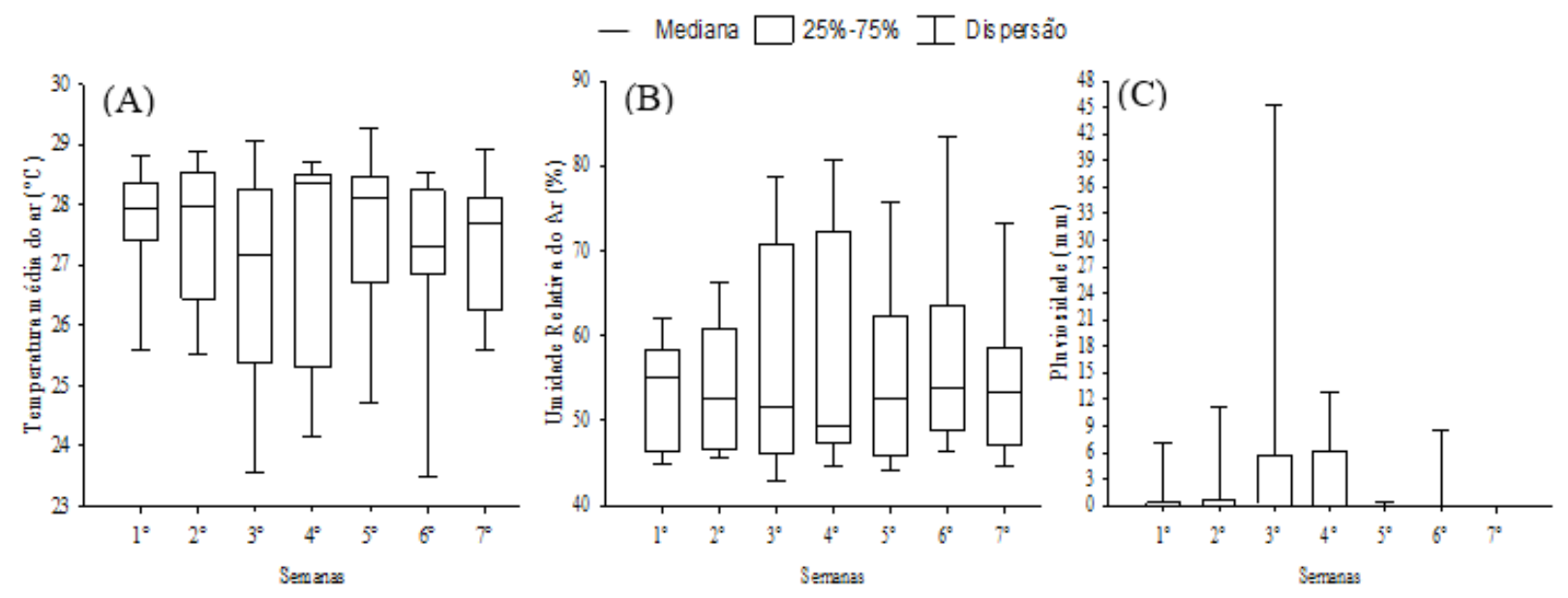

FIGURA 1: Temperatura média do ar (A), umidade relativa do ar (B) e pluviosidade (C) durante a execução do experimento, Petrolina-PE, 2015.

FIGURE 1: Average air temperature (A), relative humidity (B) and rainfall (C) during the execution of the experiment, Petrolina, PE state, 2015.

O delineamento experimental adotado foi inteiramente casualizado, com os tratamentos distribuídos em esquema fatorial $5 \times 2$, referentes a cinco doses do fertilizante de liberação controlada (FLC) - Osmocote ${ }^{\circledR}$ e substrato lavado e não lavado, com quatro repetições de 54 tubetes (mudas) por parcela.

Para a fertilização dos substratos foi utilizado o Osmocote ${ }^{\circledR}$ formulação NPK (15-10-10). As doses de adubação corresponderam a: 0 (equivalente a ausência de adubo no tratamento); 4,5; 9,0; 13,5 e 18,0 $\mathrm{kg} \mathrm{m}^{-3}$ de substrato. As doses foram baseadas nas quantidades do respectivo adubo utilizado no Setor de Produção de Mudas do CRAD. O material utilizado como substrato foi o pó de coco, material esse obtido através do beneficiamento da casca de coco verde, após trituramento, prensagem e classificado em fibras longas, fibras curtas e o pó, em uma miniusina de beneficiamento no CRAD. O pó de coco foi separado da fibra curta por meio de peneiras, utilizando-se esta parte como substrato na produção das mudas.

Para efeito de tratamento, o pó de coco foi utilizado na forma lavada e não lavada do material. Para a lavagem do substrato, o mesmo foi saturado com água de torneira em caixa d'agua de $500 \mathrm{~L}$ perfurada em sua base com furos de $7 \mathrm{~mm}$ de diâmetro, para drenagem instantânea da água. Este procedimento foi realizado até o substrato atingir a condutividade elétrica (CE) inferior a $0,1 \mathrm{dS} \mathrm{m}^{-3}$ (Tabela 1). Para se chegar nesta CE foram necessários 8,5 $\mathrm{L}$ de água de torneira para cada $1 \mathrm{~L}$ de substrato.

Quanto à caracterização química dos substratos (Tabela 1), $\mathrm{pH}$, condutividade elétrica $(\mathrm{CE}) \mathrm{e}$ capacidade de troca de cátions (CTC efetiva) foram determinados de acordo com IN 17/2007 (BRASIL, 2007) e os teores totais dos macronutrientes [nitrogênio $(\mathrm{N})$, fósforo $(\mathrm{P})$, potássio $(\mathrm{K})$, cálcio $(\mathrm{Ca})$ e magnésio $(\mathrm{Mg})$ ] e micronutrientes [boro $(\mathrm{B})$, sódio $(\mathrm{Na})$ e ferro $(\mathrm{Fe})$ ] foram determinados em extrato nítrico-perclórico (MALAVOLTA; VITTI; OLIVEIRA, 1997). Para caracterização física (Tabela 2) foram realizadas análises de umidade, densidade úmida (DU) e densidade seca (DS), capacidade de retenção de água (CRA) e porosidade total (PT) de acordo com os métodos determinados na IN 31/2008 (BRASIL, 2008a). As avaliações químicas e físicas dos substratos foram realizadas no Laboratório de Fertilidade do Solo do Instituto Agronômico de Campinas (IAC).

Após secagem ao ar durante dois dias foi realizada a adição do FLC (Osmocote ${ }^{\circledR}$ ) com as suas devidas doses ao substrato e posteriormente homogeneizados. O substrato foi colocado em tubetes de polietileno com capacidade de $120 \mathrm{~mL}$ em formato cônico, contendo cinco estrias internas, $3,7 \mathrm{~cm}$ de diâmetro interno da abertura superior, $0,8 \mathrm{~cm}$ de diâmetro interno da abertura inferior e $14 \mathrm{~cm}$ de altura.

As sementes foram previamente submetidas ao processo pré-germinativo de superação de dormência, através do desponte com tesoura de poda na região oposta ao eixo embrionário (FERREIRA; SANTOS, 1992). Após esse procedimento, as sementes foram desinfestadas com hipoclorito de sódio ( $\mathrm{NaClO}$ ) a $2 \%$, por dois minutos e, para sua remoção, enxaguadas com água destilada. Foi semeada uma semente por 
tubete, totalizando 2160 sementes. Os tubetes foram dispostos a $1,0 \mathrm{~m}$ da superfície do solo, suspensas linearmente sobre bancada de concreto e localizadas no interior do viveiro com $50 \%$ de sombreamento. A irrigação foi realizada duas vezes ao dia, totalizando lâmina diária de $20 \mathrm{~mm} \mathrm{dia}^{-1}$, fornecida por sistema de microaspersão. Não houve necessidade de controle manejo de pragas e doenças.

TABELA 1: Caracterização química do substrato pó de coco lavado e não lavado. Petrolina-PE, 2015.

TABLE 1: Chemical characterization of washed and non-washed coconut powder substrate. Petrolina, PE state, 2015.

\begin{tabular}{cccccccccccc}
\hline Substrato & $\mathrm{pH}$ & $\mathrm{CE}$ & $\begin{array}{c}\mathrm{CTC} \\
\text { (Efetiva) }\end{array}$ & $\mathrm{N}$ & $\mathrm{P}$ & $\mathrm{K}$ & $\mathrm{Ca}$ & $\mathrm{Mg}$ & $\mathrm{B}$ & $\mathrm{Na}$ & $\mathrm{Fe}$ \\
& & $\mathrm{dS} \mathrm{m}^{-3}$ & $\mathrm{mmolc} \mathrm{dm}^{-3}$ & & & $\mathrm{~g} \mathrm{~kg}^{-1}$ & & & & $\mathrm{mg} \mathrm{kg}^{-1}$ & \\
\hline Lavado & 7,8 & 0,1 & 153,7 & 6,3 & 0,4 & 5,7 & 6,5 & 1,5 & 23,5 & 0,2 & 807,1 \\
Não lavado & 6,7 & 1,6 & 69,2 & 6,1 & 0,9 & 35,1 & 5,2 & 1,6 & 28,1 & 2,4 & 931,7 \\
\hline
\end{tabular}

Em que: $\mathrm{CE}=$ condutividade elétrica; $\mathrm{CTC}=$ capacidade de troca de cátions.

TABELA 2: Caracterização física do substrato pó de coco lavado e não lavado. Petrolina-PE, 2015.

TABLE 2: Physical characterization of washed and non-washed coconut powder substrate. Petrolina, PE state, 2015.

\begin{tabular}{cccccc}
\hline Substrato & $\begin{array}{c}\text { Umidade } \\
\%(\mathrm{~m} / \mathrm{m})\end{array}$ & $\begin{array}{c}\text { Densidade Úmida } \\
\mathrm{kg} \mathrm{m}^{-3}\end{array}$ & $\begin{array}{c}\text { Densidade Seca } \\
\mathrm{kg} \mathrm{m}^{-3}\end{array}$ & $\begin{array}{c}\text { CRA } \\
\%(\mathrm{v} / \mathrm{v})\end{array}$ & $\begin{array}{c}\text { Porosidade Total } \\
\%(\mathrm{v} / \mathrm{v})\end{array}$ \\
\hline Lavado & 86,9 & 449,4 & 58,7 & 83,6 & 96,2 \\
Não lavado & 75,4 & 272,1 & 67 & 58,9 & 95,8 \\
\hline
\end{tabular}

Em que: $\mathrm{CRA}=$ capacidade de retenção de água.

Durante a execução do experimento foram registrados a porcentagem de emergência das plântulas (PE\%), diariamente até a estabilização e o índice de velocidade de emergência (IVE). Consideraramse plântulas emergidas aquelas cujos cotilédones surgiram sobre o substrato. $O$ índice de velocidade de emergência foi determinado pelo somatório do número de plântulas normais, emergidas a cada dia, conforme Maguire (1962). Aos 65 dias após a semeadura (DAS), foram determinados em 10 mudas por parcela: a) altura de plantas, expressa em $\mathrm{cm}$, medida com régua milimetrada, a partir do coleto até a gema apical; b) número de folhas, com a contagem de todas as folhas; c) diâmetro do caule, expresso em mm, medido na base do coleto, utilizando-se um paquímetro digital (Digimess ${ }^{\circledR}$ ) com precisão de $0,01 \mathrm{~mm}$; d) comprimento médio da maior raiz, expresso em centímetros, medida com régua milimetrada, a partir do coleto até a extremidade da maior raiz; e) área foliar, realizado através do programa Quant (VALE; FERNANDES; LIBERATO, 2003); f) clorofila foliar, avaliado após três leituras no clorofilômetro Spad502 (Minolta Corp.) em três folhas distintas da mesma planta; e, g) massa seca da parte aérea e da raiz, expressa em grama, pesada em balança com precisão de $0,001 \mathrm{~g}$ (Bioprecisa ${ }^{\circledR}$ ). Para determinação da massa seca, o material vegetal foi colocado em estufa com circulação forçada de ar à temperatura de $65^{\circ} \mathrm{C}$ até atingir peso constante.

Os dados foram submetidos à análise de variância pelo teste "F", para diagnóstico de efeito significativo, e os tratamentos comparados entre si pelo teste de Tukey. Para interação entre os fatores foi aplicada a análise de regressão simples seguindo as recomendações de Ferreira (2000) e Banzatto e 
Kronka (2006). Foram utilizados os programas estatísticos Assistat (SILVA; AZEVEDO, 2006) para fins de comparação de médias e o Sigma Plot® (SPSS, versão 10.0, Chicago) para elaboração dos gráficos.

\section{RESULTADOS E DISCUSSÃO}

A análise de variância não apresentou efeito significativo tanto para substrato quanto para as doses do fertilizante de liberação controlada (FLC) para as variáveis relacionadas à porcentagem de emergência (PE) e o índice de velocidade de emergência (IVE) (Tabela 3). A não significância do tratamento em relação aos dados germinativos de S. brasiliensis estão de acordo com trabalhos desenvolvidos por Meloni, Gulotta e Martinez (2008), com estresse salino para $S$. balansae, em que as mesmas foram capazes de germinar em condições de alta salinidade. A tolerância à salinidade durante a germinação é de fundamental importância para o estabelecimento de plantas que crescem em regiões com solo árido e potencialmente salinos (UNGAR, 1995). Em regiões áridas, a germinação geralmente ocorre durante a estação das chuvas, quando os níveis de salinidade do solo são normalmente reduzidos (EL-KEBLAWY, 2004). Em Anacardiaceae, de uma forma geral, o processo de germinação está diretamente relacionado com a temperatura e precipitação. Após a dispersão anemocórica, as sâmaras de S. brasilienses permanecem em estado de repouso fisiológico até quando a precipitação garante balanço hídrico do solo (MELONI; GULOTTA; MARTINEZ, 2008).

TABELA 3: Porcentagem de emergência (PE), índice de velocidade de emergência (IVE) de mudas de Schinopsis brasiliensis produzidas em substrato lavado e não lavado sob diferentes doses de fertilizante de liberação controlada (FLC). Petrolina-PE, 2015.

TABLE 3: Percentage of emergence (PE), emergence velocity index (EVI) of Schinopsis brasiliensis seedlings produced in washed and non-washed substrate under different doses of controlled release fertilizer (CRF). Petrolina, PE state, 2015.

\begin{tabular}{ccc}
\hline Causa de variação & PE & IVE \\
\cline { 2 - 3 } & $\%$ & - \\
\hline Substrato (S) ("F") & $1,05^{\text {ns }}$ & $0,03^{\text {ns }}$ \\
\hline Lavado & $65,41 \mathrm{a}$ & $2,24 \mathrm{a}$ \\
Não lavado & $62,29 \mathrm{a}$ & $2,20 \mathrm{a}$ \\
\hline DMS & 6,19 & 0,33 \\
\hline Doses de FLC (D) ("F”) & $2,02^{\text {ns }}$ & $1,95^{\text {ns }}$ \\
\hline Interação (S)x(D) & $2,39^{\text {ns }}$ & $1,98^{\text {ns }}$ \\
\hline CV (\%) & 15,02 & 23,43 \\
\hline
\end{tabular}

Em que: $\mathrm{CV}=$ coeficiente de variação; $\mathrm{DMS}$ = diferença mínima significativa; ns = não significativo. Médias seguidas de letras distintas, nas colunas, são estatisticamente diferentes entre si pelo teste de Tukey.

De acordo com os resultados da análise de variância não houve efeito da interação substrato $\mathrm{x}$ doses de FLC para as variáveis número de folhas e clorofila foliar (Tabela 4). Para as demais variáveis, o efeito da interação foi significativo ao nível de $1 \%$ de probabilidade. 
TABELA 4: Número de folhas (NF), altura de plantas (ALT), área foliar (AF), clorofila foliar (CF), diâmetro do caule (DC), comprimento médio da maior raiz (CMMR), massa seca parte áerea (MSPA) e massa seca da raiz (MSR) de mudas de Schinopsis brasiliensis produzidas em substrato lavado e não lavado sob diferentes doses de fertilizante de liberação controlada (FLC). Petrolina-PE, 2015.

TABLE 4: $\quad$ Number of leaves (NL), plant height (PH), leaf area (LA), leaf chlorophyll (LC), stem diameter (SD), average length of roots (ALR), mass of dry shoot (MDS) and root (MDR) of Schinopsis brasiliensis seedlings produced in washed and non-washed substrate under different doses of controlled release fertilizer (CRF). Petrolina, PE state, 2015.

\begin{tabular}{ccccccccc}
\hline \multirow{2}{*}{ Causa de variação } & NF & ALT & AF & CF & DC & CMMR & MSPA & MSR \\
\cline { 2 - 8 } & & $-\mathrm{cm}^{-1}-$ & $-\mathrm{cm}^{2}-$ & -- Icf-- & $-\mathrm{cm}^{-1}-$ & $-\mathrm{cm}^{-1}-$ & g planta $^{-1}$ & g planta $^{-1}$ \\
\hline Substrato (S) (“F”) & $22,00^{* *}$ & $48,04^{* *}$ & $179,94^{* *}$ & $11,00^{* *}$ & $134,6^{* *}$ & $156,57^{* *}$ & $48,90^{* *}$ & $218,80^{* *}$ \\
\cline { 3 - 9 } Lavado & $10,65 \mathrm{a}$ & $10,59 \mathrm{a}$ & $405,85 \mathrm{a}$ & $121,13 \mathrm{a}$ & $1,76 \mathrm{a}$ & $20,58 \mathrm{a}$ & $4,20 \mathrm{a}$ & $1,94 \mathrm{a}$ \\
Não lavado & $8,59 \mathrm{~b}$ & $7,23 \mathrm{~b}$ & $155,61 \mathrm{~b}$ & $109,26 \mathrm{~b}$ & $1,17 \mathrm{~b}$ & $12,87 \mathrm{~b}$ & $1,55 \mathrm{~b}$ & $0,44 \mathrm{~b}$ \\
\hline DMS & 0,89 & 0,99 & 38,12 & 7,308 & 0,1 & 1,25 & 0,48 & 0,2 \\
\hline Doses de FLC (D) (“F”) & $63,05^{* *}$ & $31,09^{* *}$ & $50,75^{* *}$ & $263,42^{* *}$ & $44,07 * *$ & $14,98^{* *}$ & $34,26 * *$ & $28,71^{* *}$ \\
Interação (S)x(D) & $0,93^{\text {ns }}$ & $2,80^{* *}$ & $14,09^{* *}$ & $2,21^{\text {ns }}$ & $11,37 * *$ & $5,12 * *$ & $7,61 * *$ & $17,05 * *$ \\
\hline CV (\%) & 14,41 & 17,19 & 21,01 & 9,82 & 10,91 & 11,65 & 25,91 & 26,84 \\
\hline
\end{tabular}

Em que: $\mathrm{CV}=$ coeficiente de variação; $\mathrm{DMS}=$ diferença mínima significativa; $\mathrm{ns}=$ não significativo; $* *$ = significativo a $1 \%$ de probabilidade $(p<0,01)$; Médias seguidas de letras distintas, nas colunas, são estatisticamente diferentes entre si pelo teste de Tukey.

Para o número de folhas (Tabela 4), observa-se que as mudas conduzidas em substrato lavado apresentaram média superior estatisticamente àquelas conduzidas em substrato não lavado, com incremento de 19,34\%. Com o procedimento de lavagem do pó de coco, ocorreu um decréscimo no nível salino do substrato $\left(\mathrm{CE}=0,1 \mathrm{dS} \mathrm{m}^{-3}\right)$, e o tratamento que não passou por esse procedimento, apresentou elevadas concentrações de potássio e sódio (Tabela 1), elementos esses que quando disponibilizados em grandes quantidades podem conferir às plantas sintoma semelhante ao excesso de salinidade, além da ocorrência de deficiência induzida de cálcio e magnésio (PRADO, 2008). Em condições de estresse salino, é comum ocorrerem alterações morfológicas e anatômicas nas plantas, que refletem na redução da transpiração como alternativa para manter a baixa absorção de solução salina, e uma dessas adaptações é a redução do número de folhas (TAIZ; ZEIGER, 2006). A salinidade excessiva pode causar toxidez análoga à adubação excessiva e potencialmente modificar o metabolismo do sistema radicular, abreviando a síntese e/ou translocação de hormônios sintetizados na raiz, os quais são necessários ao metabolismo foliar; como resultado, o crescimento das folhas é atrasado (SILVA et al., 2008).

Em relação à altura de plantas (Tabela 4), observou-se um maior crescimento das mudas de baraúna quando conduzidas no substrato lavado, apresentando altura média $(10,59 \mathrm{~cm})$ superior estatisticamente às mudas no substrato sem lavagem $(7,23 \mathrm{~cm})$. Percebe-se um incremento para essa variável de $31,72 \%$, evidenciando-se o desempenho consequente da alta salinidade do substrato não lavado. $\mathrm{O}$ excesso de sais na rizosfera das plantas pode exercer efeitos maléficos no crescimento, podendo levar à morte das plantas em virtude do maior efeito osmótico externo à raiz e restrição ao fluxo de água para as plantas, necessário para sobreviverem em condições de estresse salino (RHOADES; KANDIAH; MASHALI, 2000). Neves, Carvalho e Rodrigues (2004) em estudo testando níveis de salinidade no crescimento inicial de Spondias tuberosa, também da família das Anacardiaceae, obtiveram redução de incremento em altura em 50\% na dose de 27,3 $\mathrm{mmol} \mathrm{L}^{-1}$ de $\mathrm{NaCl}$.

A interação entre substrato e doses de FLC apresentou comportamento quadrático para a altura de plantas apresentando valores máximos estimados de 8,98 e 13,98 cm com as doses de 12,86 e 11,34 kg m m $^{-3}$ de Osmocote ${ }^{\circledR}$, para o substrato não lavado (Figura 2A) e lavado (Figura 2B), respectivamente. 

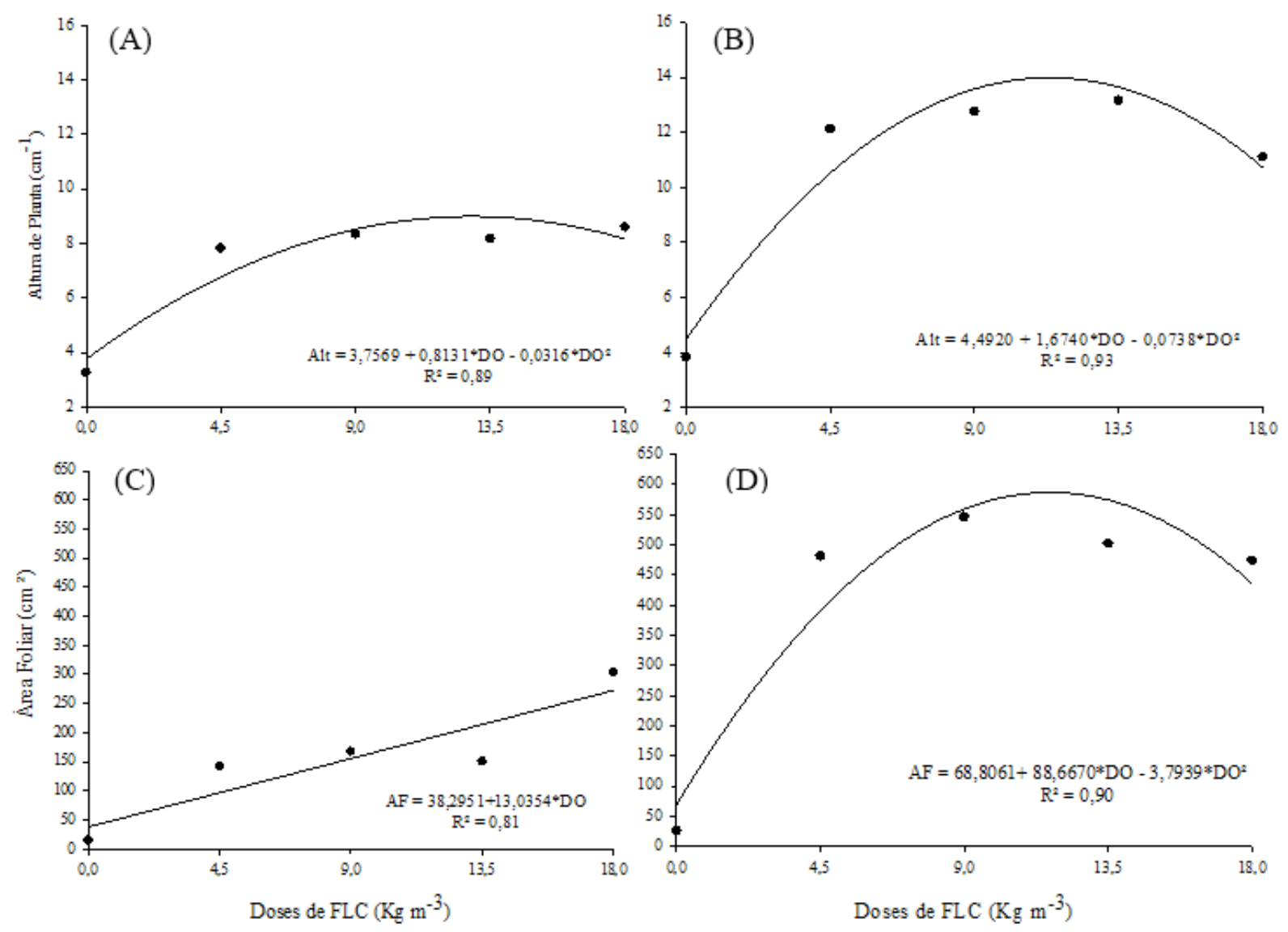

FIGURA 2: Altura de planta (A e B) e área foliar (C e D) de mudas de Schinopsis brasiliensis em função da interação do substrato e doses de fertilizante de liberação controlada (FLC) ${ }^{\circledR}$. Petrolina-PE, 2015. (A) e (C) substrato não lavado; (B) e (D) substrato lavado. Petrolina-PE, 2015.

FIGURE 2: Plant height (A and B) and leaf area (C and D) of Schinopsis brasiliensis seedlings in funtion of the interaction substrate and doses of controlled release fertilizer (CRF). Petrolina-PE, 2015. (A) and (C) non-washed substrate; (B) and (D) washed substrate. Petrolina, PE state, 2015.

As doses ideais encontradas no presente trabalho contrariam os dados obtidos por Kratka e Correia (2015), que trabalhando com mudas de Myracrodruon urundeuva, também Anacardiaceae, apresentaram a morte das mesmas, em dose máxima de $8 \mathrm{~kg} \mathrm{~m}^{-3} \mathrm{de}_{\text {Osmocote }}{ }^{\circledR}$. Porém, esses resultados conflitantes podem estar relacionados com a própria característica do adubo, o qual, apesar de ser um adubo de liberação controlada, pode apresentar aspectos singulares de acordo com as condições de temperatura e umidade do meio, no caso o substrato, em que a umidade ou temperatura elevada acarretará uma maior liberação dos nutrientes podendo causar uma possível fitotoxidade às mudas ainda jovens.

Em relação à área foliar, devido ao comportamento linear da interação substrato e doses de FLC, a maior área foliar quando o substrato não foi lavado $\left(303,65 \mathrm{~cm}^{2}\right)$ ocorreu na dose máxima em estudo (Figura 2C), ao passo que para o substrato lavado a maior área foliar $\left(586,86 \mathrm{~cm}^{2}\right)$ correspondeu à dose estimada de $11,68 \mathrm{~kg} \mathrm{~m}^{-3}$ (Figura 2D). Nota-se que ocorreu um incremento de 93,18\%, para as mudas produzidas em substrato lavado em relação ao não lavado na maior dose estudada. A redução da área foliar decorre, provavelmente, da diminuição do volume das células (SOUZA, 1995) que, em associação com reduções na atividade fotossintética, contribui para a adaptação das culturas à salinidade. Diminuições na área foliar decorrente da elevação da salinidade na solução do substrato, também se relacionam com um possível mecanismo endógeno de controle que a planta desenvolve em condições de estresse para diminuir a transpiração. A maior área foliar em mudas adubadas com o adubo de liberação controlada é o resultado do aumento do número de folhas observado em cada muda (Figura 3A). O maior desenvolvimento dos tecidos foliares em resposta a adubação, tanto pelo aumento do número quanto aumento da área média das folhas é 
determinante para o aumento da capacidade fotossintetizante das plantas e está diretamente relacionado ao maior desenvolvimento das mudas. A adequada fertilização promove o aumento da área foliar das plantas, resultando no aumento da eficiência de crescimento e desenvolvimento foliar (BLEVINS; PRESCOTT; ALLEN, 2005). Aumentos no índice de área foliar associado com adubação resultam no aumento da interceptação de luz, sendo responsável pelo aumento da produção de biomassa das plantas (KLOOSTER et al., 2012).

Tendo em vista o parâmetro clorofila foliar (Tabela 4), observa-se que as mudas conduzidas em substrato lavado apresentaram maior índice de clorofila foliar, aferindo-se um incremento de 9,79\% em relação àquelas produzidas em substrato não lavado. Esse maior incremento provavelmente está relacionado com a maior disponibilidade de nutrientes, devido à melhoria de $99,09 \%$ na CTC do substrato $(153,7 \mathrm{mmolc}$ $\left.\mathrm{dm}^{-3}\right)$ (Tabela 1), e, com isso, os nutrientes que estão intimamente ligados à clorofila na folha estão também disponíveis em uma maior quantidade, a exemplo do nitrogênio. Observa-se na Figura 3B que um aumento na dosagem do fertilizante, promove uma elevação no índice de clorofila foliar.
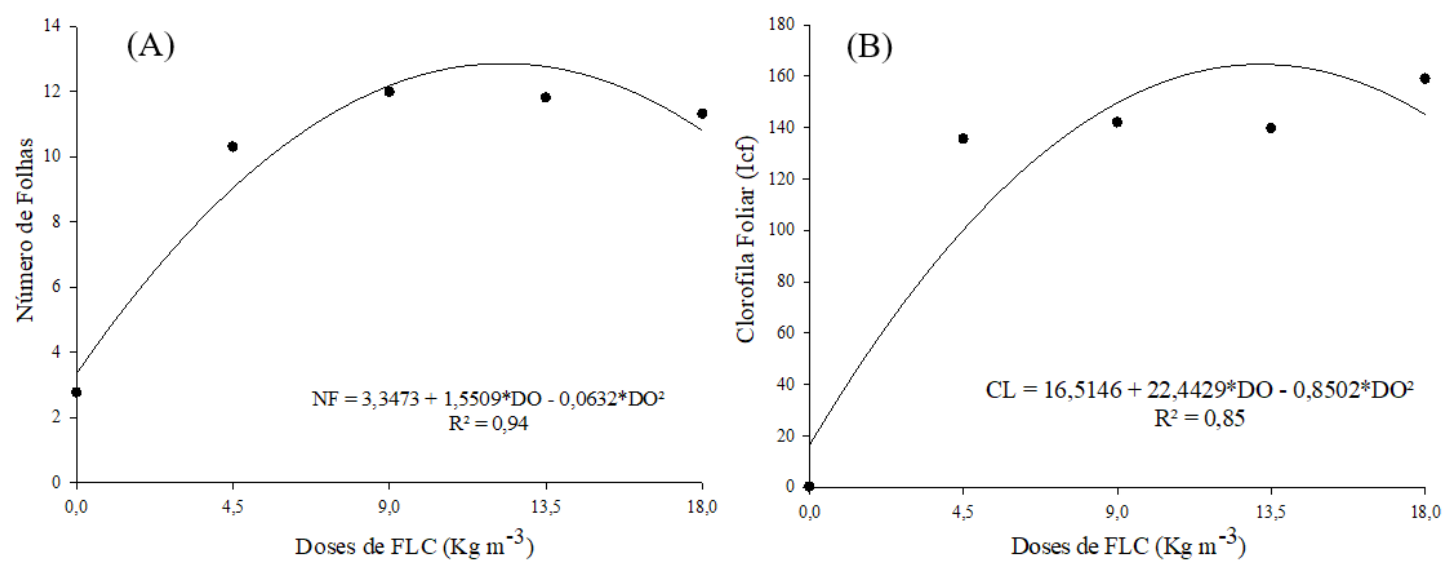

FIGURA 3: Número de folhas (A) e clorofila foliar (B) de mudas de Schinopsis brasiliensis em função das doses do fertilizante de liberação controlada (FLC). Petrolina-PE, 2015.

FIGURE 3: Number of leaves (A) and leaf chlorophyll (B) of seedlings Schinopsis brasiliensis in function of doses of controlled release fertilizer (CRF). Petrolina, PE state, 2015.

Para o diâmetro do caule das mudas de baraúna, observa-se que as plantas produzidas no substrato lavado apresentaram média estatística superior com 50,42\% de incremento em relação àquelas cultivadas em substrato não lavado (Tabela 4). Este resultado pode ser oriundo do efeito da alta condutividade elétrica do substrato não lavado (Tabela 1). De acordo com Ayers e Westcot (1999), toda e qualquer planta sensível aos efeitos salinos apresenta perda potencial do seu rendimento quando a concentração de sais do substrato for alta. $\mathrm{O}$ contato das raízes com o meio adversamente salino contribui para maior e mais rápida absorção de sais que provocam depressividade a todos os órgãos das plantas, inclusive ao caule (ARAÚJO; SÁ; LIMA, 2000).

$\mathrm{Na}$ interação entre substrato e doses de fertilizante de liberação controlada, o diâmetro do caule apresentou valores máximos estimados de $1,4 \mathrm{e} 2,19 \mathrm{~cm}$ com as doses de $18 \mathrm{e} 12,92 \mathrm{k} \mathrm{g} \mathrm{m}^{-3}$, para substrato não lavado (Figura 4A) e substrato lavado (Figura 4B), respectivamente. Comparando os tratamentos do substrato, nas respectivas doses máximas de FLC, observa-se que o substrato lavado aumentou o diâmetro do caule das mudas de S. brasiliensis de $192 \%$, em detrimento do incremento de apenas $55 \%$ na dose máxima do FLC. Percebe-se que a diminuição dos sais do substrato e a disponibilidade gradual de nutrientes permite um ganho positivo em diâmetro das mudas. 

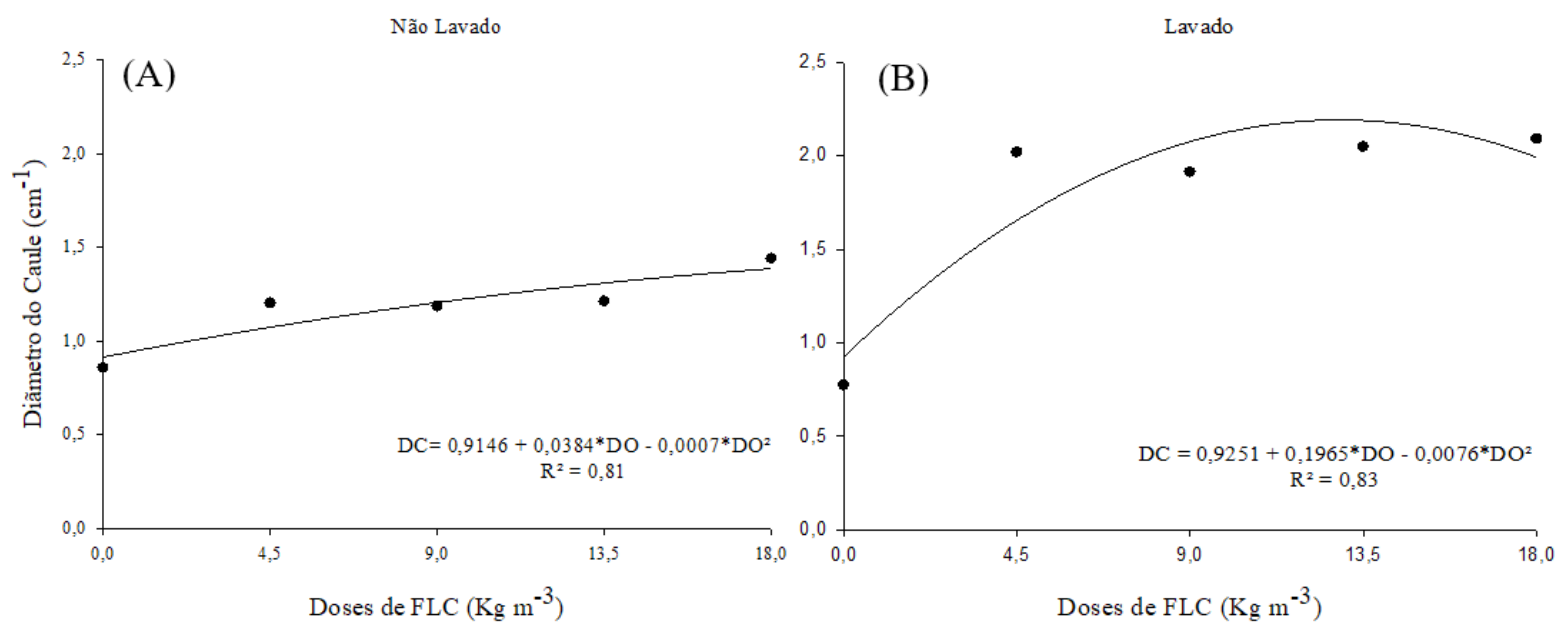

FIGURA 4: Diâmetro do caule (A e B) de mudas de Schinopsis brasiliensis em função da interação substrato e doses de fertilizante de liberação controlada (FLC). Petrolina-PE, 2015. (A) substrato não lavado; (B) substrato lavado.

FIGURE 4: Stem diameter (A and B) of Schinopsis brasiliensis seedlings in funtion of the interaction substrate and doses of controlled release fertilizer (CRF). Petrolina, PE state, 2015. (A) non washed substrate; (B) washed substrate.

Observando o comprimento médio da maior raiz (CMMR) (Tabela 4), percebe-se que o substrato lavado promoveu maior expansão radicular $(20,58 \mathrm{~cm})(\mathrm{p}<0,01)$, em comparação às mudas de baraúna produzidas no substrato sem ser lavado, com incremento de $59,9 \%$. O efeito adverso da salinidade sobre a absorção e a utilização de nutrientes está relacionado com o aumento da pressão osmótica na solução absorvida e com a acumulação de certos íons no tecido vegetal em concentrações tóxicas, ocasionando diminuição no crescimento do sistema radicular (SILVA et al., 2008). A interação entre substrato e doses de fertilizante de liberação controlada teve comportamento quadrático para o CMMR, apresentando valores máximos estimados de 16,76 e 21,73 cm com as doses de 12,30 e 11,35 $\mathrm{kg} \mathrm{m}^{-3} \mathrm{de} \mathrm{FLC}$, para o substrato não lavado (Figura 5A) e lavado (Figura 5B), respectivamente.
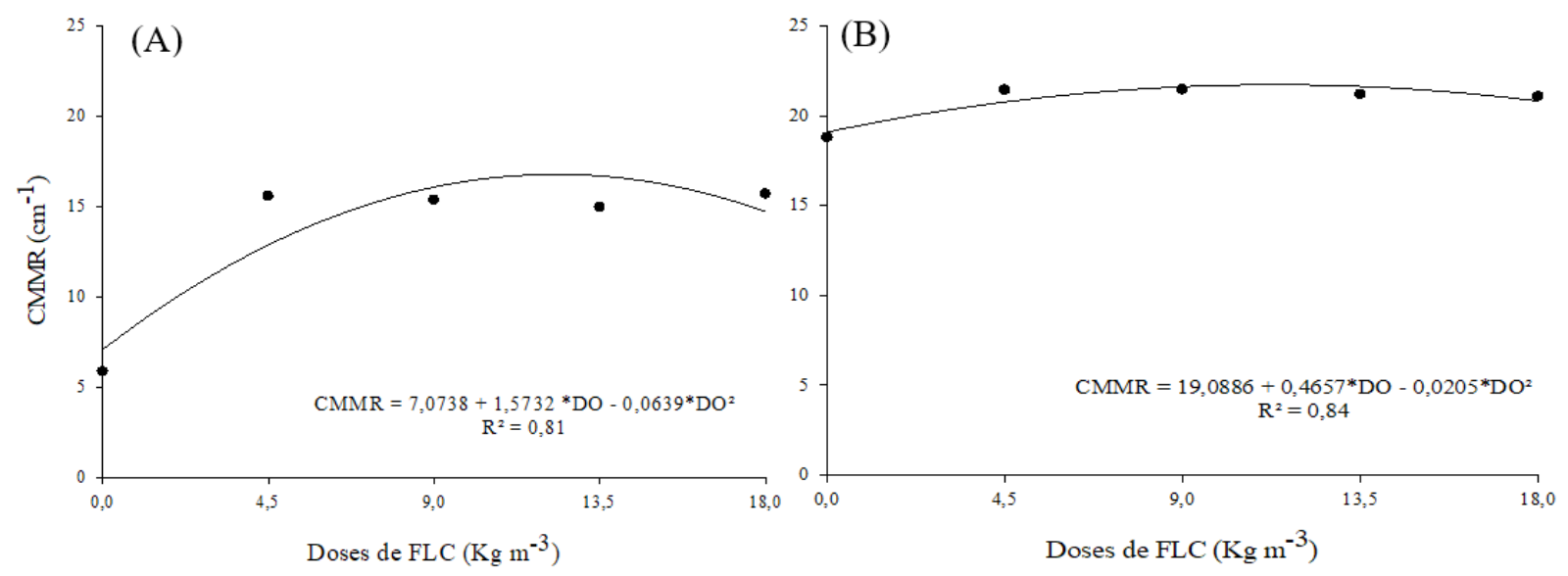

FIGURA 5: Comprimento médio da maior raiz (CMMR) (A e B) de mudas de Schinopsis brasiliensis em função da interação substrato e doses de fertilizante de liberação controlada (FLC). Petrolina-PE, 2015. (A) substrato não lavado; (B) substrato lavado.

FIGURE 5: Average length of roots (ALR) (A and B) of Schinopsis brasiliensis seedlings in funtion of the interaction substrate and doses of controlled release fertilizer (CRF). Petrolina, PE state, 2015. (A)non washed substrate; (B) washed substrate. 
A interação entre substratos e diferentes doses de fertilizante de liberação controlada apresentou comportamento quadrático para a massa seca da parte aérea (MSPA), apresentando valores máximos estimados de 2,24 e 5,86 cm com as doses de 17,99 e 13,02 $\mathrm{kg} \mathrm{m}^{-3}$ de FLC, para o substrato não lavado (Figura 6A) e substrato lavado (Figura 6B), respectivamente. Para a massa seca da raiz (MSR), no substrato não lavado (Figura 6C), com aumento das doses do FLC houve incremento de forma linear, estimando-se valor máximo na dose de $18 \mathrm{~kg} \mathrm{~m}^{-3}$, enquanto para o substrato lavado (Figura 6D) houve um aumento nos valores de massa seca radicular, seguido de progressivo decréscimo, atingindo, maior acúmulo na dose estimada de $11,36 \mathrm{~kg} \mathrm{~m}^{-3}$.

O menor quantitativo de fertilizante necessário para obtenção de máxima massa seca no substrato lavado pode ser atribuído às próprias condições proporcionadas por esse tratamento em relação à capacidade de troca de cátions, que facilitou a absorção dos nutrientes, liberados gradualmente pelo FLC, principalmente o nitrogênio. Segundo Yanai et al. (1996), a disponibilidade de N estimula o crescimento e a atividade radicular, com reflexos positivos na absorção de outros nutrientes. Fato esta que colabora com as observações de Venturin (1999) com mudas de angico-amarelo (Peltophorum dubium), em que o sistema radicular das plantas foi significativamente afetado pela omissão de nitrogênio, em relação ao tratamento completo.

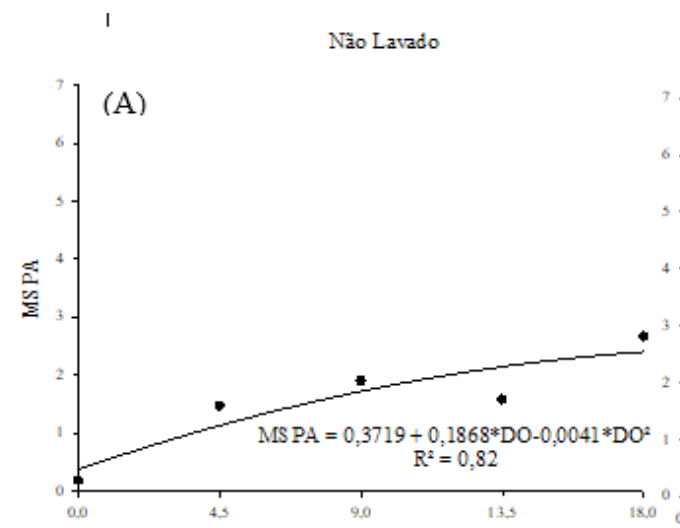

Lavado

(B)

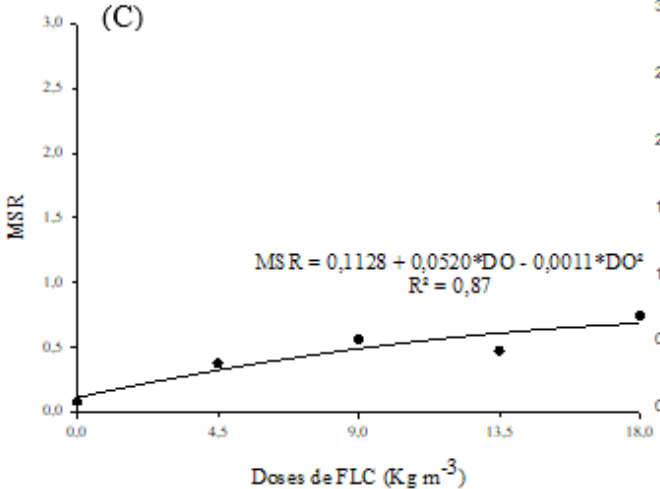

(D)

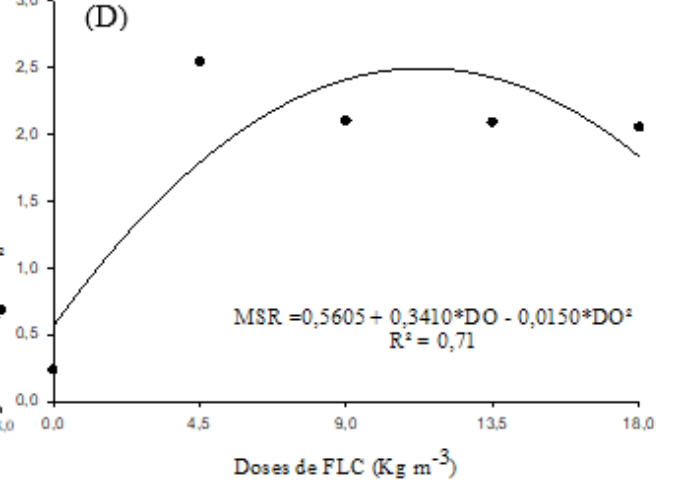

FIGURA 6: Massa seca parte áerea (MSPA) (A e B) e massa seca da raiz (MSR) (C e D) de mudas de Schinopsis brasiliensis em função da interação substrato e doses de fertilizante de liberação controlada (FLC). Petrolina-PE, 2015. (A) e (C) substrato não lavado; (B) e (D) substrato lavado.

FIGURE 6: Mass of dry shoot (MDS) (A and B) and root (MDR) (C and D) of Schinopsis brasiliensis seedlings in funtion of the interaction substrate and doses of controlled release fertilizer (CRF). Petrolina, PE state, 2015. (A) and (C) non-washed substrate; (B) and (D) washed substrate.

\section{CONCLUSÃO}

A alta condutividade elétrica do substrato pó de coco compromete o desenvolvimento inicial de mudas de baraúna (Schinopsis brasiliensis), indicando-se a necessidade da lavagem do substrato para se 
realizar a produção de mudas. A lavagem do pó de coco em associação com o uso de fertilizante de liberação controlada proporciona melhor formação de mudas. As doses do fertilizante de liberação controlada influenciam positivamente o crescimento inicial das mudas de baraúna, incrementando todas as variáveis em estudo. $\mathrm{O}$ fertilizante de liberação controlada pode ser recomendado para a formação de mudas de baraúna, na dose de até $12,75 \mathrm{~kg} \mathrm{~m}^{-3}$.

\section{REFERÊNCIAS}

ARAÚJO, D. C.; SÁ, J. R.; LIMA, E. M. Efeito do volume de água e da cobertura morta sobre o crescimento inicial do maracujazeiro-amarelo. Revista Brasileira de Engenharia Agrícola e Ambiental, Campina Grande, v. 4, n. 1, p. 121-124, 2000.

AYERS, R. S.; WESTCOT, D. W. A qualidade de água na agricultura. Campina Grande: Universidade Federal da Paraíba, 1999. 53 p.

BANZATTO, D. A.; KRONKA, S. N. Experimentação agrícola. 4. ed. Jaboticabal: FUNEP, 2006. 237 p. BLEVINS, D. P.; PRESCOTT, C. E.; ALLEN, H. L. The effects of nutrition and density on growth, foliage biomass, and growth efficiency of high-density fire-origin lodgepole pine in Central British Columbia. Journal of Forest Research, Ottawa, v. 35, p. 2851-2859, 2005.

BOSCO, M. R. O. et al. Influência do estresse salino na composição mineral da berinjela. Revista Ciência Agronômica, Fortaleza, v. 40, n. 1, p. 157-164, 2009.

BRASIL. Ministério da Agricultura, Pecuária e Abastecimento. Instrução normativa $\mathrm{n}^{\circ} 17$ de 21 de maio de 2007/SDA. Aprova os métodos analíticos oficiais para análise de substratos e condicionadores de solos.

Diário Oficial da República Federativa do Brasil, Brasília, DF, 24 maio 2007. Seção 1, p. 8.

BRASIL. Ministério da Agricultura, Pecuária e Abastecimento. Instrução Normativa n. ${ }^{\circ} 31$, de 24 de outubro de 2008. Altera os subitens 3.1.2, 4.1 e 4.1.2, do Anexo à Instrução Normativa n. ${ }^{\circ}$ 17, de 21 de maio de 2007/SDA. Diário Oficial da República Federativa do Brasil, Brasília, DF, 24 out. 2008a, Seção 1, p.20. BRASIL. Ministério do Meio Ambiente. Instrução normativa ${ }^{\circ}$ 06, de 23 de setembro de 2008. Reconhece espécies da flora brasileira ameaçadas de extinção. Diário Oficial da União, Brasília, DF, 23 set. 2008b. Seção 1,8 p.

BRASIL. Ministério do Meio Ambiente. Portaria MMA n ${ }^{\circ} 443$, de 17 de dezembro de 2014. Diário Oficial da União, Brasília, DF, 17 dez. 2014. Seção 3, 25 p.

CALDEIRA, M. V. W. et al. Biossólido na composição de substrato para a produção de mudas de Tectona grandis. Floresta, Curitiba, v. 23, n. 12, p. 77-84, 2012.

CRUZ, F. R. S.; ANDRADE, L. A.; FEITOSA, R. C. Produção de mudas de umbuzeiro (Spondias tuberosa Arruda Câmara) em diferentes substratos e tamanho de recipientes. Ciência Florestal, Santa Maria, v. 26, n. 1, p. 69-80, 2016.

EL-KEBLAWY, A. Salinity effects on seed germination of the common desert range grass, Panicum turgidum. Seed Science and Technology, Zurique, v. 32, n. 1, p. 943-948, 2004.

FERREIRA, P. V. Estatística experimental aplicada à Agronomia. 3. ed. Maceió: UFAL, 2000. 604 p.

FERREIRA, S. A. N.; SANTOS L. A. Viabilidade de sementes de pupunha (Bactris gasipaes Kunth.).

Acta Amazonica, Manaus, v. 22, n. 3, p. 303-307, 1992.

GONZAGA, T. W. C. et al. Crioconservação de sementes de aroeira (Astronium urundeuva Engl.), e baraúna (Schinopsis brasiliensis Engl.). Revista Brasileira de Produtos Agroindustriais, Campina Grande, v. 5, n. 2, p. 145-154, 2003.

KLOOSTER, W. S. et al. Growth and physiology of deciduous shade trees in response to controlled-release fertilizer. Scientia Horticulturae, Amsterdam, v. 35, p. 71-79, 2012.

KRATKA, P. C.; CORREIA, C. R. M. A. Crescimento inicial de aroeira-do-sertão (Myracrodruon urundeuva allemão) em diferentes substratos. Revista Árvore, Viçosa, MG, v. 39, n. 3, p. 551-559, 2015.

KRATZ, D.; WENDLING, A. C. N.; SOUZA, P. V. D. Substratos renováveis na produção de mudas de Eucalyptus benthamii. Ciência Florestal, Santa Maria, v. 23, n. 4, p. 607-621, 2013.

MAGUIRE, J. D. Speed of germination-aid in selection and evaluation for seedling emergence and vigor. Crop Science, Madison, v. 2, n. 1, p. 176-177, 1962.

MAIA G. N. Caatinga: árvores, arbustos e suas utilidades. São Paulo: Leitura \& Arte, 2004. 413 p.

Ci. Fl., v. 28, n. 3, jul. - set., 2018 
MALAVOLTA, E.; VITTI, G. C.; OLIVEIRA, S. A. Avaliação do estado nutricional das plantas: princípios e aplicações. Piracicaba: Potafos, 1997. 201 p.

MARTINELLI, G.; MORAES, M. A. Livro vermelho da flora do Brasil. Rio de Janeiro: Andrea Jakobsson; Instituto de Pesquisas Jardim Botânico do Rio de Janeiro, 2013. 1100 p.

MATIAS, G. C. S. et al. Avaliação de substratos comerciais para a produção de mudas de alface. Horticultura Brasileira, Brasília, v. 17. n. 2, p. 159-162, 1999.

MELONI, D. A.; GULOTTA, M. R.; MARTINEZ, C. A. Salinity tolerance in Schinopsis quebracho colorado: seed germination, growth, ion relations and metabolic responses. Journal of Arid Environments, London, v. 72, n. 1, p. 1785-1792, 2008.

MENDONÇA, V. et al. Diferentes ambientes e Osmocote ${ }^{\circledR}$ na produção de mudas de tamarindeiro (Tamarindus indica). Ciência e Agrotecnologia, Lavras, v. 32, n. 2, p. 391-397, 2008.

NEVES, O. S. C.; CARVALHO, J. G.; RODRIGUES, C. R. Crescimento e nutrição mineral de mudas de umbuzeiro (Spondias tuberosa arr. Cam.) submetidas a níveis de salinidade em solução nutritiva. Ciência Agrotecnica, Lavras, v. 28, n. 5, p. 997-1006, 2004.

NUNES, C. C. S.; SOUZA, D. R. Sobrevivência de quatro espécies lenhosas nativas cultivadas em solos degradados, Cruz das Almas, Bahia. Revista Magistra, Cruz das Almas, v. 23, n. 1-2, p. 11-16, 2011.

OLIVEIRA, A. B.; HERNANDEZ, F. F. F.; ASSIS JÚNIOR, R. N. Absorção de nutrientes em mudas de berinjela cultivadas em pó de coco verde. Revista Caatinga, Mossoró, v. 22, n. 2, p. 139-143, 2009.

OLIVEIRA, F. A. et al. Desempenho de cultivares de alface submetidas a diferentes níveis de salinidade da água de irrigação. Revista Brasileira de Engenharia Agrícola e Ambiental, Campina Grande, v. 15, n. 8, p. 771-777, 2011.

PAES, J. B.; MORAIS, V. M.; LIMA, C. R. Resistência natural de nove madeiras do semiárido brasileiro a fungos xilófagos em condições de laboratório. Revista Árvore, Viçosa, MG, v. 28, n. 2, p. 275-282, 2004. PRADO, R. M. Nutrição de plantas. São Paulo: UNESP, 2008. 407 p.

RHOADES, J. D.; KANDIAH, A.; MASHALI, A. M. Uso de águas salinas para produção agrícola. Campina Grande: FAO, 2000. 117 p.

ROSSA, U. B. et al. Fertilizante de liberação lenta no desenvolvimento de mudas de Eucalyptus grandis. Revista Floresta, Curitiba, v. 45, n. 1, p. 85-96, 2015.

SILVA, F. A. S. E.; AZEVEDO, C. A. V. A. New Version of the Assistat-Statistical Assistance Software. In: WORLD C ONGRESS ON COMPUTERS IN AGRICULTURE, 4., Orlando, 2006. Anais... Orlando: American Society of Agricultural Engineers, 2006. p. 393-396.

SILVA, S. M. S. et al. Desenvolvimento e produção de duas cultivares de mamoneira sob estresse salino. Revista Brasileira de Engenharia Agrícola e Ambiental, Campina Grande, v. 12, n. 4, p. 335-342, 2008. SIQUEIRA FILHO, J. A. et al. Guia de campo de árvores da Caatinga. Petrolina: Franciscana, 2009. $64 \mathrm{p}$.

SOUZA, M. R. Comportamento do feijoeiro (Phaseolus vulgaris L. CV Eriparza) submetido a diferentes níveis de salinidade da água de irrigação. 1995. 94f. Dissertação (Mestrado em Engenharia Agrícola) - Universidade Federal de Campina Grande, Campina Grande, 1995.

TAIZ, L.; ZEIGER, E. Fisiologia Vegetal. 3. ed. Porto Alegre: ARTMED, 2006. 719 p.

UNGAR, I. A. Seed germination and seed-bank ecology of halophytes. In: KIGEL, J.; GALILI, G. (Ed.). Seed Development and Germination. New York: Marcel Dekker, 1995. p. 599-629.

VALE, F. X. R.; FERNADES, E. I. F.; LIBERATO, J. R. Quant-A software for plant disease severity assessment. In: INTERNATIONAL CONGRESS OF PLANT PATHOLOGY, 8., 2003. Abstracts... [s. 1.: s. n], 2003. p. 105.

VENTURIN, N. Adubação mineral do angico amarelo (Peltophorum dubium) (Spreng) Taub.). Pesquisa Agropecuária Brasileira, Brasília, v. 34, n. 3, p. 441-448, 1999.

XAVIER, K. R F. et al. Impactos pós-fogo na regeneração natural em um fragmento de floresta ombrófila aberta no município de Areia, Paraíba, Brasil. Revista brasileira de Biociências, Porto Alegre, v. 9, n. 3, p. 257-264, 2011.

YANAI, J. et al. Effects of inorganic nitrogen application on the dynamics of the soil solution composition in the root zone of maize. Plant Soil, Dordretch, v. 180, n. 1, p. 1-9, 1996. 